\title{
BMJ Open Future trends in the prevalence of severe activity limitations among older adults in Europe: a cross-national population study using EU-SILC
}

Sergei Scherbov, ${ }^{1,3,4}$ Daniela Weber ${ }^{1,2}$

To cite: Scherbov S, Weber D. Future trends in the prevalence of severe activity limitations among older adults in Europe: a cross-national population study using EU-SILC. BMJ Open 2017;7:e017654. doi:10.1136/ bmjopen-2017-017654

- Prepublication history and additional material for this paper are available online. To view please visit the journal (http:// dx.doi.org/10.1136/bmjopen2017-017654).

Received 8 May 2017 Revised 19 July 2017 Accepted 3 August 2017

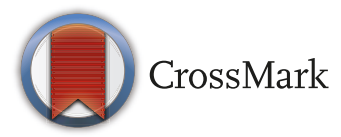

${ }^{1}$ Wittgenstein Centre (IIASA, VID/ ÖAW, WU), International Institute for Applied Systems Analysis, Laxenburg, Austria

${ }^{2}$ Health Economics and Policy Division, Vienna University of Economics and Business, Vienna, Austria

${ }^{3}$ Russian Presidential Academy of National Economyand Public Administration (RANEPA),

Moscow, Russian Federation

${ }^{4}$ Vienna Institute of Demography, Austrian Academy of Science, Vienna, Austria

Correspondence to

Dr Daniela Weber;

weberd@iiasa.ac.at

\section{ABSTRACT}

Objective To project the proportion of population 65+ years with severe long-term activity limitations from 2017 to 2047.

Design Large population study.

Setting Population living in private households of the European Union (EU) and neighbouring countries.

Participants Participants from the EU Statistics on Income and Living Conditions aged 55 years and older and living in one of $26 \mathrm{EU}$ and neighbouring countries, who answered the health section of the questionnaire. Outcome measures Prevalence of severe long-term activity limitations of particular subpopulations (ie, 55+, $65+, 75+$ and $85+$ years) by sex and country.

Results We find a huge variation in the prevalence of self-reported severe long-term limitations across Europe for both sexes. However, in 2017, about $20 \%$ of the female population aged 65 years and above and about $16 \%$ of their male counterparts are expected to report severe long-term activity limitations after accounting for differences in reporting. Accounting for cultural differences in reporting, we expect that European countries will have about 21\% (decile 1: 19.5\%; decile 9: $22.9 \%$ ) of female and about $16.8 \%$ (decile 1: $15.4 \%$; decile 9: $18.1 \%$ ) of male $65+$ years population with severe long-term activity limitations by 2047.

Conclusions Overall, despite the expected increase of life expectancy in European countries, our results suggest almost constant shares of older adults with severe longterm activity limitations within the next 30 years.

\section{INTRODUCTION}

Worldwide populations are growing older. In upper middle-income and high-income countries, life expectancy is increasing and fertility rates are declining, leading to an increase of older populations. However, there is a lack of evidence whether these demographic changes are accompanied by an increase of frail or morbid people. The health status of older population is of raising public interest and a broadly discussed issue since many countries fear a rise in economic costs caused by ageing.

\section{Strengths and limitations of this study}

- We used data on 26 European countries collected annually between 2008 and 2014.

- Applying the Sullivan method, we computed life expectancy without severe long-term activity limitations (healthy life years (HLYs)) by sex and 5 -year age groups.

- We model the ratio of HLYs and life expectancy to predict prevalence of severe activity limitations among older adults.

- Cultural differences in self-reports are acknowledged, so we used a random intercept approach to consider those properly.

During the last decades, a large body of literature focused on health trends, which were often analysed with indicators using health-specific life expectancies. ${ }^{1-3}$ Research on trends in healthy life years (HLYs) and disability-free life expectancy showed an inconsistent pattern. For instance, in the early 2000s, healthy life expectancy showed only little change for European men and women in contrast to their life expectancy, ${ }^{4}$ whereas it increased significantly between the early 1980s and 2000s in Austria. ${ }^{5}$ Other studies showed that in the USA, higher educated population experienced some compression of morbidity, whereas their lower educated counterparts showed an expansion. ${ }^{6}$

There are inequalities in health expectancies at older ages across the European Union (EU) and even within countries, and there are discrepancies between men and women. ${ }^{1}$ Even though women benefit from their mortality advantage over men when it comes to HLYs, the situation is sometimes the opposite. Women in general report higher prevalence of disabilities and frailty. ${ }^{7}$ Some research already explored this health-survival paradox. ${ }^{89}$ 
Less research was focused on the impact of possible future trends in healthy and disability-free life expectancy on the socioeconomic development of a country. For instance, are European health systems prepared for higher shares of older adults? Should we expect higher proportions of unhealthy older population?

The objective of this study is to provide an outlook on the future health status of older population measured by living with severe long-term limitations in daily activities. Based on the EU Statistics on Income and Living Conditions (SILC) survey, we project the share of the $65+$ years population living with severe long-term activity limitations for 26 European countries by 2047.

\section{DATA AND METHOD \\ Data}

We used the EU-SILC data, which are conducted annually within EU member states and a few additional European states. ${ }^{10}$ This cross-sectional and longitudinal microdata provide information on income, poverty, social exclusion and living conditions. Eurostat has coordinated the EU-SILC data since 2003, whereas national statistical institutes have collected the information, first in 6 countries and by 2014 in 31 countries. ${ }^{11}$ Although the sampling procedure varies across countries, the samples are considered nationally representative of individuals aged at least 16 years living in private households. ${ }^{10}{ }^{11}$ In our study, we focus on the global activity limitation indicator (GALI), which was designed for monitoring HLYs (ie, life expectancy without long-term activity limitations) within the EU. ${ }^{12}$ This measure of general activity limitations was shown to be significantly associated with other health measures such as functional limitations, activities of daily living and instrumental activity of daily living. ${ }^{13}$ Since 2008, GALI addresses the long-term activity limitations with the question 'For at least the past 6 months, to what extent have you been limited because of a health problem in activities people usually do?'. There are some minor variations in the wording for the kind of activities across some countries ranging from usual, normal to daily activities (see ref 14). Therefore, we recoded the response categories 'limited, but not severely' and 'not limited at all' as having no severe difficulties and 'severely limited' as with severe limitations. Moreover, there might be variations in self-reports across cultures due to the uncertainty in defining 'limited, but not severely', so our recoding additionally addresses this potential bias.

We investigated the EU-SILC data provided by Eurostat restricting on the population aged at least 55 years from 2008 to 2014 on an aggregated level by country, sex and 5-year age groups. We also used sex-specific life tables provided by Eurostat for each country and each of our corresponding survey years. ${ }^{15}$ In addition, we used sex-specific life tables and age-specific and sex-specific population projections from 2015 to 2050 provided by the United Nations following the medium projection variant assumptions. ${ }^{16}$

\section{Methods}

Prevalences of bad general health status are proxied by self-reported presence of long-term activity limitations (ie, the GALI). Sample weights are considered to account for non-response, so that the data are nationally representative for the non-institutionalised population. Using the sex-specific and age group-specific prevalence rates and Eurostat life tables, we applied the Sullivan method to compute health-specific life expectancy, that is, remaining life expectancy without severe long-term activity limitations (also called healthy life years) for each country by 5 -year age groups between 2008 to $2014 .{ }^{17}$ We determined sex-specific and age-specific HLY for each survey year and computed $r$, the ratio of HLY and life expectancy. ${ }^{418}$

Since our estimation of HLY is based on the self-reported activity limitation status, country-specific cultural norms may play a crucial role in explaining big difference in the prevalence of severe long-term activity limitations. The generosity of social security systems may also play an important role in differences between countries. In this study, we tried to minimise this bias due to reporting style with regressing the ratio of HLY to life expectancy by sex for 26 upper middle-income and high-income countries across Europe using random intercept model. ${ }^{19}$ The significant group effect was identified with likelihood ratio tests for men and women. The between country variance explained more than $80 \%$ of the variance in $r$, the ratio of HLY to life expectancy, which supported our motivation to extinguish the potential cultural differences in self-reports.

Furthermore, we tested the importance of time, hence if there is a change in the proportion of remaining life years spent without severe long-term activity limitations (HLY/LE) over the years. While women showed no significant change across time, we identified a small significant increase of $r$ among men. Nevertheless, this increase was on average $<0.025$ units per year, which can be read as a prevalence increase of $<0.5 \%$ points per year. Therefore, we decided to ignore this time effect for simplicity reasons and run the following model separately by sex

$$
\operatorname{logit}\left(r_{i c}\right)=\beta_{0}+\sum_{i=2}^{8} \beta_{i} D_{i c}+u_{0 c}+\varepsilon_{i c}
$$

with $D_{i c}$ a dummy variable for the 5-year age groups, indicating the first level aggregated by age group and year and $c$ indicates the country group (second level).

Next, we used the sex-specific United Nations life tables for the years 2015-2050 to project HLY by age for those years using estimated $\bar{r}_{i}$, which represents the age group-specific ratio averaged across all countries. In order to perform comparative analysis, we used a sex-specific and age group-specific overall $\bar{r}_{i}$ for all countries, rather than applying the country-specific estimated $\overline{r_{i c}}$ because of the huge variation in country effects, which might be defined by cultural and norm differences in countries under consideration. ${ }^{20}$ 


\section{4}

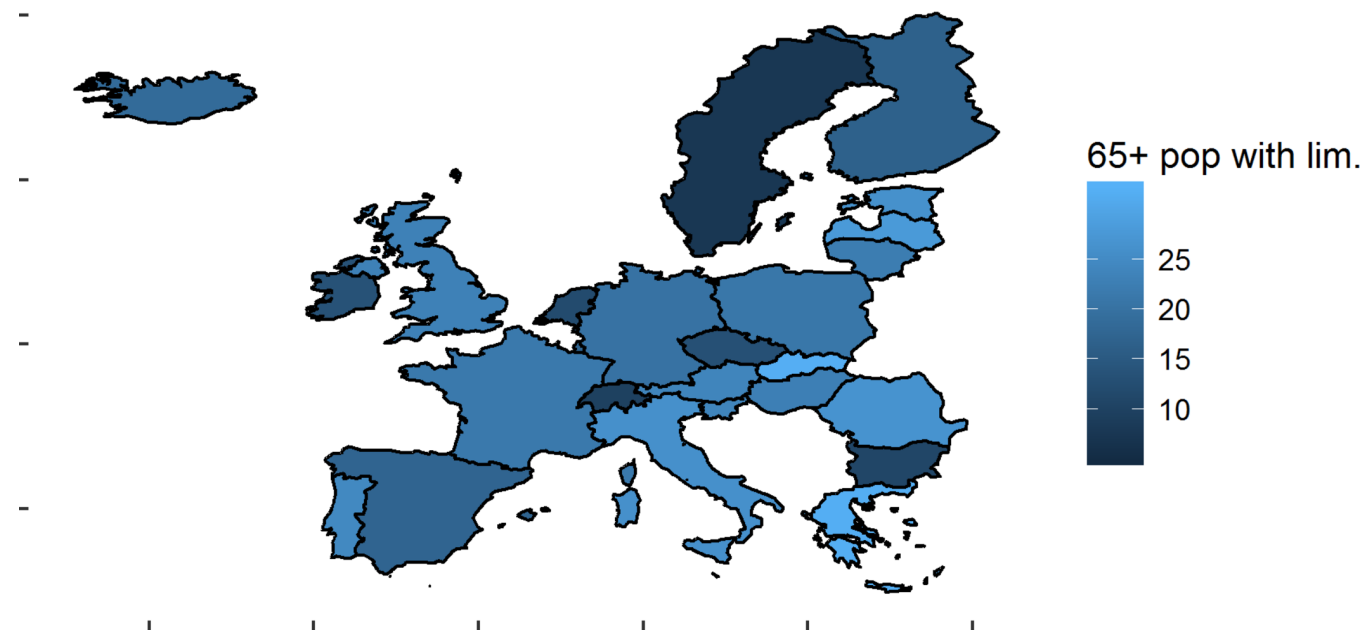

Figure 1 Self-reported severe activity limitations among at least 65 years old women across 26 European countries in 2014.

Having $\bar{r}_{i}$ and the sex-specific projected life expectancy by age, we were able to calculate sex-specific HLY by age and to estimate the prevalence rate of people with severe long-term activity limitations, subsequently. Moreover, we projected the prevalence rate of people with severe long-term activity limitations and the proportion of older adults with severe long-term activity limitations from 2017 to 2047 using age-specific and sex-specific United Nations population projections.

Since we applied the overall $\bar{r}_{i}$ for all countries, the differences emerging in projected trends of prevalence of severe long-term activity limitations depend only on population age composition and projected life expectancies. Moreover, while life expectancy is increasing and the ratio of HLY and life expectancy remains constant over time, HLY has to increase and it can decrease only with higher age. Hence, overall sex-specific and age group-specific good general health increases as well, which implies a decline in severe long-term activity limitations.
In addition, we performed some sensitivity analysis considering uncertainty in the estimates and provided a prediction interval around projected prevalences.

\section{RESULTS}

Comparing observed prevalence rates of severe long-term activity limitations of older adults (ie, $65+$ years population) across Europe, we identified huge disparities in the health of older adults across the investigated upper middle-income and high-income countries for both men and women (figures 1 and 2). For instance, in 2012 in Sweden, only $9.99 \%$ of the female $65+$ years population reported severe long-term limitations, whereas about $34.15 \%$ of their counterparts in Slovakia reported bad health (table 1). The range is a bit narrower for the male $65+$ years population, the prevalence rates were between $6.44 \%$ and $27.6 \%$ in Malta and Slovakia, subsequently (table 1). In all countries, more women than men

\section{4}

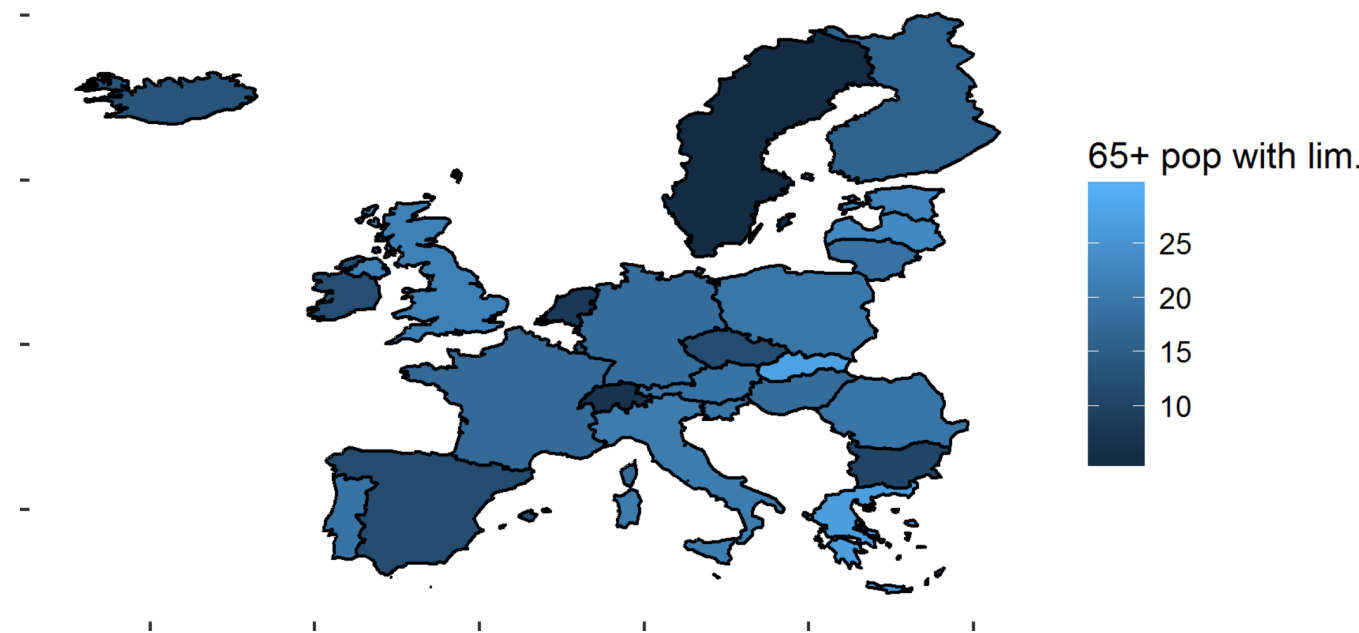

Figure 2 Self-reported severe activity limitations among at least 65 years old men across 26 European countries in 2014. 
Table 1 Prevalence rates of women and men aged at least 55, 65, 75 and 85 years with severe long-term activity limitations for 26 European countries in 2012

\begin{tabular}{|c|c|c|c|c|c|c|c|c|}
\hline \multirow[b]{2}{*}{ Country } & \multicolumn{4}{|c|}{ Women } & \multicolumn{4}{|c|}{ Men } \\
\hline & $55+$ & $65+$ & $75+$ & $85+$ & $55+$ & $65+$ & $75+$ & $85+$ \\
\hline Austria & 19.1 & 23.3 & 32.6 & 46.4 & 17.3 & 19.9 & 28.5 & 40.6 \\
\hline Bulgaria & 8.6 & 11.5 & 16.3 & 19.8 & 7.0 & 9.9 & 15.4 & 26.5 \\
\hline Czech Republic & 12.6 & 15.9 & 25.4 & 33.6 & 10.1 & 11.6 & 19.4 & 27.9 \\
\hline Estonia & 22.0 & 27.8 & 36.7 & 54.8 & 19.5 & 23.2 & 31.2 & 36.5 \\
\hline Finland & 12.7 & 15.3 & 21.8 & 24.9 & 11.4 & 14.6 & 21.3 & 29.3 \\
\hline France & 19.3 & 24.6 & 32.5 & 44.7 & 14.8 & 18.6 & 27.3 & 35.6 \\
\hline Germany & 22.8 & 27.0 & 38.4 & 53.3 & 19.3 & 21.1 & 25.2 & 39.8 \\
\hline Greece & 24.9 & 30.8 & 39.8 & 47.0 & 18.3 & 23.4 & 30.9 & 38.9 \\
\hline Hungary & 17.3 & 22.9 & 32.4 & 42.5 & 14.8 & 18.6 & 25.0 & 38.9 \\
\hline Iceland & 21.7 & 22.1 & 23.1 & 22.9 & 12.8 & 15.1 & 18.6 & 33.3 \\
\hline Ireland & 9.3 & 11.6 & 15.0 & 27.6 & 11.2 & 14.4 & 18.5 & 27.4 \\
\hline Italy & 20.8 & 27.2 & 37.6 & 49.3 & 15.0 & 19.8 & 27.5 & 34.4 \\
\hline Latvia & 15.6 & 20.6 & 28.0 & 33.9 & 13.4 & 18.9 & 21.8 & 35.9 \\
\hline Lithuania & 19.0 & 25.0 & 33.8 & 61.4 & 15.1 & 18.8 & 25.1 & 40.3 \\
\hline Luxembourg & 13.0 & 17.0 & 21.0 & 20.0 & 11.1 & 13.2 & 18.7 & 27.2 \\
\hline Malta & 8.5 & 12.2 & 23.0 & 36.9 & 5.2 & 6.4 & 12.4 & 15.1 \\
\hline Netherlands & 9.6 & 11.6 & 16.6 & 17.6 & 9.4 & 10.4 & 15.5 & 16.4 \\
\hline Poland & 15.8 & 21.4 & 30.5 & 43.9 & 14.8 & 19.1 & 26.0 & 39.9 \\
\hline Portugal & 19.8 & 25.5 & 33.3 & 44.6 & 14.5 & 18.9 & 25.6 & 33.0 \\
\hline Romania & 21.7 & 28.3 & 39.7 & 55.6 & 15.1 & 20.5 & 31.4 & 42.4 \\
\hline Slovakia & 24.9 & 34.1 & 47.8 & 59.1 & 20.5 & 27.6 & 45.0 & 78.4 \\
\hline Slovenia & 23.5 & 30.2 & 41.0 & 47.0 & 18.4 & 21.3 & 19.6 & 38.5 \\
\hline Spain & 13.3 & 17.8 & 26.0 & 37.4 & 9.9 & 12.3 & 18.0 & 27.6 \\
\hline Sweden & 10.2 & 10.0 & 12.7 & 15.3 & 7.2 & 8.0 & 14.0 & 22.5 \\
\hline Switzerland & 10.2 & 11.3 & 14.7 & 18.9 & 8.1 & 8.7 & 10.7 & 15.3 \\
\hline UK & 21.8 & 26.4 & 35.1 & 44.8 & 17.1 & 19.8 & 27.4 & 37.4 \\
\hline
\end{tabular}

reported severe long-term activity limitations, although women tend to have higher life expectancy than men.

However, we observed a very pronounced difference in the prevalence of severe long-term activity limitations also among the countries where remaining life expectancy at age 65 years often differs very little. Considering these variations between countries, our random intercept regression showed a decline in the ratio of HLY to life expectancy by age, as expected. Moreover, the clear decline by age was of almost the same magnitude for both sexes (see online supplementary tables S1 and S2). Hence, men and women experienced the same speed of health deterioration.

We showed that the so-called burden of unhealthy population is very similar across European countries (see table 2), if we exclude cultural differences in reporting and consider only differences in age structure and life expectancy.

Controlling for cultural bias in self-reports, we noticed some changes over time in the ranking of countries with the highest and lowest level of older adults with severe activity limitations. For instance, Lithuania followed by Latvia had the highest shares of unhealthy 65 years and older adults in 2017. In 2047, Germany and the Netherlands can be expected to have the highest proportion of men above age 65 years with severe long-term activity limitations.

Furthermore, our results demonstrate almost no increase of the proportion of people with severe longterm activity limitations for most European countries participating in EU-SILC. These results are valid both for men and women (see table 2). Within 30 years, the magnitude of change in the proportion of people $65+$ years is less than $2.5 \%$ points among the female population and even smaller among men ( $2 \%$ points).

In the online supplementary figures S1 and S2, we show the prediction intervals of the proportion of men and women at ages $65+$ years based on uncertainty in parameter estimations related to the age effects. Very little uncertainty in age effects is translated into relatively 
Table 2 Prevalence rates of at least 65 years old women and men with severe long-term activity limitations for 26 European countries in 2017, 2027, 2037 and 2047; in parentheses change since 2017.

\begin{tabular}{|c|c|c|c|c|c|c|c|c|}
\hline \multirow[b]{2}{*}{ Country } & \multicolumn{4}{|c|}{ Women } & \multicolumn{4}{|c|}{ Men } \\
\hline & 2017 & 2027 & 2037 & 2047 & 2017 & 2027 & 2037 & 2047 \\
\hline Austria & 20.68 & $20.21(-0.47)$ & $19.96(-0.72)$ & $21.40(0.72)$ & 16.17 & $15.93(-0.24)$ & $15.96(-0.21)$ & $17.25(1.08)$ \\
\hline Bulgaria & 21.27 & $21.70(0.43)$ & $21.95(0.68)$ & $21.66(0.39)$ & 17.11 & $17.29(0.18)$ & $17.32(0.21)$ & $17.12(0.01)$ \\
\hline $\begin{array}{l}\text { Czech } \\
\text { Republic }\end{array}$ & 20.02 & $20.89(0.87)$ & $21.49(1.47)$ & $20.63(0.61)$ & 15.83 & $16.46(0.63)$ & $16.7(0.87)$ & $16.16(0.33)$ \\
\hline Estonia & 21.49 & $21.21(-0.28)$ & $21.73(0.24)$ & $21.86(0.37)$ & 16.85 & $16.48(-0.37)$ & $16.74(-0.11)$ & $16.80(-0.05)$ \\
\hline Finland & 19.80 & $20.37(0.57)$ & $21.86(2.06)$ & $21.87(2.07)$ & 15.48 & $16.21(0.73)$ & $17.30(1.82)$ & $17.24(1.76)$ \\
\hline France & 20.26 & $19.81(-0.45)$ & $20.71(0.45)$ & $21.52(1.26)$ & 15.94 & $16.08(0.14)$ & $16.76(0.82)$ & $17.20(1.26)$ \\
\hline Germany & 21.22 & $20.61(-0.61)$ & $20.52(-0.7)$ & $22.28(1.06)$ & 16.56 & $16.20(-0.36)$ & $16.31(-0.25)$ & $17.79(1.23)$ \\
\hline Greece & 21.01 & $20.72(-0.29)$ & $20.51(-0.5)$ & $21.06(0.05)$ & 17.11 & $16.74(-0.37)$ & $16.39(-0.72)$ & $16.58(-0.53)$ \\
\hline Hungary & 21.05 & $21.34(0.29)$ & $21.87(0.82)$ & $21.01(-0.04)$ & 16.64 & $16.91(0.27)$ & $17.09(0.45)$ & $16.51(-0.13)$ \\
\hline Iceland & 19.71 & $18.95(-0.76)$ & $20.06(0.35)$ & 21.01 (1.3) & 15.43 & $15.15(-0.28)$ & $16.30(0.87)$ & $16.75(1.32)$ \\
\hline Ireland & 19.25 & $19.37(0.12)$ & $19.78(0.53)$ & $19.86(0.61)$ & 15.43 & $15.57(0.14)$ & $15.82(0.39)$ & $15.97(0.54)$ \\
\hline Italy & 20.62 & $20.36(-0.26)$ & $20.19(-0.43)$ & $21.51(0.89)$ & 16.27 & $16.20(-0.07)$ & $16.11(-0.16)$ & $17.07(0.8)$ \\
\hline Latvia & 21.98 & $21.52(-0.46)$ & $21.74(-0.24)$ & $22.22(0.24)$ & 17.40 & $16.93(-0.47)$ & $17.05(-0.35)$ & $17.22(-0.18)$ \\
\hline Lithuania & 22.21 & $21.24(-0.97)$ & $21.41(-0.8)$ & $22.61(0.4)$ & 18.27 & $16.92(-1.35)$ & $17.05(-1.22)$ & $17.57(-0.7)$ \\
\hline Luxembourg & 20.51 & $19.26(-1.25)$ & $19.29(-1.22)$ & $20.24(-0.27)$ & 15.84 & $15.22(-0.62)$ & $15.45(-0.39)$ & $16.43(0.59)$ \\
\hline Malta & 19.68 & $20.74(1.06)$ & $21.43(1.75)$ & $21.09(1.41)$ & 15.55 & $16.28(0.73)$ & $16.93(1.38)$ & $16.58(1.03)$ \\
\hline Netherlands & 19.76 & $19.90(0.14)$ & $20.68(0.92)$ & 22.09 (2.33) & 15.60 & $15.86(0.26)$ & $16.50(0.9)$ & $17.62(2.02)$ \\
\hline Poland & 20.14 & $19.91(-0.23)$ & $21.77(1.63)$ & $21.03(0.89)$ & 15.98 & $15.85(-0.13)$ & $17.05(1.07)$ & $16.43(0.45)$ \\
\hline Portugal & 20.73 & $20.45(-0.28)$ & $20.55(-0.18)$ & $21.12(0.39)$ & 16.53 & $16.33(-0.2)$ & $16.48(-0.05)$ & $16.88(0.35)$ \\
\hline Romania & 21.24 & $21.15(-0.09)$ & $21.27(0.03)$ & $21.36(0.12)$ & 16.98 & $16.88(-0.1)$ & $16.88(-0.1)$ & $16.95(-0.03)$ \\
\hline Slovakia & 20.29 & $20.21(-0.08)$ & 21.29 (1) & $20.80(0.51)$ & 16.11 & $16.10(-0.01)$ & $16.86(0.75)$ & $16.38(0.27)$ \\
\hline Slovenia & 20.76 & $20.14(-0.62)$ & $20.85(0.09)$ & $21.45(0.69)$ & 15.95 & $15.77(-0.18)$ & $16.56(0.61)$ & $16.91(0.96)$ \\
\hline Spain & 20.69 & $19.86(-0.83)$ & $19.73(-0.96)$ & $20.64(-0.05)$ & 16.40 & $15.88(-0.52)$ & $15.81(-0.59)$ & $16.53(0.13)$ \\
\hline Sweden & 20.05 & $20.71(0.66)$ & $20.95(0.9)$ & $21.18(1.13)$ & 15.68 & $16.49(0.81)$ & $16.67(0.99)$ & $16.94(1.26)$ \\
\hline Switzerland & 20.12 & $19.74(-0.38)$ & $19.82(-0.3)$ & $21.04(0.92)$ & 15.71 & $15.69(-0.02)$ & $15.91(0.2)$ & $16.91(1.2)$ \\
\hline UK & 20.37 & $20.25(-0.12)$ & $20.36(-0.01)$ & $21.25(0.88)$ & 16.07 & $16.13(0.06)$ & $16.20(0.13)$ & $16.87(0.8)$ \\
\hline
\end{tabular}

narrow prediction intervals. The trends in proportion of people with severe long-term activity limitations are almost constant for most countries (eg, Estonia, Greece and Hungary). However, Germany and some other countries showed a slight increase and only a few countries such as Poland showed a slight decline in the proportion of people with severe long-term activity limitations (see online supplementary figures S1 and S2).

\section{DISCUSSION}

In this analysis of EU-SILC data, we investigated self-reports in severe activity limitations of older adults in 26 upper middle-income and high-income countries across Europe. Our results showed that HLY differ considerably, which might be explained by self-reports. Countries with relatively similar levels of mortality, life expectancies and health systems are not expected to differ much in HLY apart from cultural differences in self-reports. For instance, Germany and the Netherlands are very similar in their remaining life expectancy at age 65 years (21 years for females and about 18 years for men), but they differ in terms of remaining life years without severe activity limitations; there is a gap of 3 years for women and about 2 years for men (women: 15 years Germany, 18.4 years Netherlands; men: 13.8 years Germany, 18.4 years Netherlands). Moreover, these potential cultural differences in self-reports are supported by our investigations in the ratio of HLY and life expectancy. Country differences explained $80 \%$ of the difference in the ratio. Another issue that may lead to the differences in self-reporting is the generosity of the welfare system. In more generous systems, higher reports of severe long-term activity limitations might go together with the easier access to disability benefits. There might be also 'true' differences in self-reported health attributed to different life styles in European countries or differences in genetics. However, one 
would expect that morbidity and disability are also relatively close, if the levels of mortality are very close.

We also showed that the ratio of remaining life expectancy without severe long-term activity limitations to the total remaining life expectancy does not change with time for women and only little for men and that the so-called burden of unhealthy population is very similar across European countries once potential cultural differences in self-reports are excluded. Furthermore, the general concern that ageing is accompanied by an increase of disability may occur in the absolute level only, but more importantly, the proportion of adults aged 65+ years with severe long-term activity limitations will remain almost constant in the upcoming years, although total life expectancy is expected to increase. A recent study on disabilities (ie, difficulties with activities of daily living) suggests similar trends of no increase in the prevalence for England and Wales by 2025, but an increase of older people with care needs in absolute numbers. ${ }^{21}$ Interestingly, research on trends between 1991 and 2011 using different English data showed that while more life years are spent healthy, less severe disabilities are increasing. ${ }^{22}$ This increase in less severe disabilities might be in consequence of variations in self-reports as also identified in our study or an increase in obesity.

However, there may be important policy implications derived from our results on trends in severe long-term activity limitations. Even though the trends in proportion of people with limitations will remain constant, the absolute number of people with severe long-term activity limitations will definitely increase since the number of people at older ages is expected to increase in most European countries. It might require several measures to accommodate the needs of an increasing number of people with activity limitations such as expanding infrastructure for disabled people in the public as well as private area, training of medical specialists and care professionals.

Some limitations of this study should be noted. First of all, EU-SILC survey does not cover the institutionalised population. Even though we have included sample weights to control for non-response, there was nothing we could do to include the institutionalised population within our projections. Another limitation is the application of Sullivan method to compute HLY rather than using panel data, and calculating multistate life tables, but this is more a data limitation. Nevertheless, our study on future trends in the prevalence of severe longterm activity limitations confirms a recent comment by Kenneth Rockwood. He stated that we should not expect to spend our whole life in good health, ${ }^{23}$ rather European countries might expect more older adults with severe long-term activity limitations but, in relative terms, the number stays constant.

Contributors SS and DW contributed to conception and design. DW conducted the data analysis and modelling. Both authors contributed to drafting the manuscript and revising it critically.
Funding This work was supported by the European Research Council (Grant Number ERC2012-AdG 323947-Re-Ageing).

Competing interests None declared.

Provenance and peer review Not commissioned; externally peer reviewed.

Data sharing statement Anonymised, non-identifiable participant-level survey data are freely available for academic researchers after successful application from Eurostat. Survey data on an aggregate level are freely downloadable from Eurostat.

Open Access This is an Open Access article distributed in accordance with the Creative Commons Attribution Non Commercial (CC BY-NC 4.0) license, which permits others to distribute, remix, adapt, build upon this work non-commercially, and license their derivative works on different terms, provided the original work is properly cited and the use is non-commercial. See: http://creativecommons.org/ licenses/by-nc/4.0/

(C) Article author(s) (or their employer(s) unless otherwise stated in the text of the article) 2017. All rights reserved. No commercial use is permitted unless otherwise expressly granted.

\section{REFERENCES}

1. Jagger $\mathrm{C}$, Weston $\mathrm{C}$, Cambois $\mathrm{E}$, et al. Inequalities in health expectancies at older ages in the European Union: findings from the Survey of Health and Retirement in Europe (SHARE). J Epidemiol Community Health 2011;117705.

2. Berger N, Robine JM, Ojima T, et al. Harmonising summary measures of population health using global survey instruments. J Epidemiol Community Health 2016;70:1039-44.

3. Jagger C, Gillies C, Moscone F, et al. Inequalities in healthy life years in the 25 countries of the European Union in 2005: a cross-national meta-regression analysis. Lancet 2008;372:2124-31.

4. Jagger C, McKee M, Christensen K, et al. Mind the gap-reaching the European target of a 2-year increase in healthy life years in the next decade. Eur J Public Health 2013;23:829-33.

5. Doblhammer G, Kytir J. Compression or expansion of morbidity? Trends in healthy-life expectancy in the elderly Austrian population between 1978 and 1998. Soc Sci Med 2001;52:385-91.

6. Crimmins EM, Saito Y. Trends in healthy life expectancy in the United States, 1970-1990: gender, racial, and educational differences. Soc Sci Med 2001;52:1629-41.

7. Harttgen K, Kowal P, Strulik H, et al. Patterns of frailty in older adults: comparing results from higher and lower income countries using the Survey of Health, Ageing and Retirement in Europe (SHARE) and the Study on Global AGEing and Adult Health (SAGE). PLoS One 2013;8:e75847

8. Van Oyen H, Nusselder W, Jagger C, et al. Gender differences in healthy life years within the EU: an exploration of the "healthsurvival" paradox. Int J Public Health 2013;58:143-55.

9. Cambois E, Solé-Auró A, Brønnum-Hansen H, et al. Educational differentials in disability vary across and within welfare regimes: a comparison of 26 European countries in 2009. J Epidemiol Community Health 2016;70:331-8.

10. Arora VS, Karanikolos M, Clair A, et al. Data Resource Profile: The European Union Statistics on Income and Living Conditions (EUSILC). Int J Epidemiol 2015;44:451-61.

11. Eurostat. EU statistics on income and living conditions (EUSILC) methodology - data collection - Statistics Explained. http://ec.europa.eu/eurostat/statistics-explained/index.php/ EU_statistics_on_income_and_living_conditions_(EU-SILC) methodology_\%Ë2\%80\%93_data_collection (accessed 10 Jul 2017).

12. van Oyen $\mathrm{H}$, Van der Heyden J, Perenboom R, et al. Monitoring population disability: evaluation of a new Global Activity Limitation Indicator (GALI). Soz Praventivmed 2006;51:153-61.

13. Berger $\mathrm{N}$, Van Oyen $\mathrm{H}$, Cambois $\mathrm{E}$, et al. Assessing the validity of the global activity limitation indicator in fourteen European countries. BMC Med Res Methodol 2015;15:1.

14. EHLEIS team. 2011. Assessment of the GALI question used in SILC since 2008. France. www.eurohex.eu.

15. European Commission. Eurostat. 2016 http://ec.europa.eu/eurostat/ data/database (accessed 28 Oct 2016).

16. United Nations. World Population Prospects: The 2015 Revision. New York, NY: Department of Economic and Social Affairs, Population Division, 2015. http://esa.un.org/unpd/wpp/.

17. Sullivan DF. A single index of mortality and morbidity. HSMHA Health Rep 1971;86:347-54.

18. Sanderson WC, Scherbov S. Remeasuring Aging. Science 2010;329:1287-8. 
19. Raudenbush SW, Bryk AS. Hierarchical Linear Models: Applications and Data Analysis Methods. 2nd ed. Thousand Oaks, California: Sage Publications, Inc, 2002.

20. Hardy MA, Acciai F, Reyes AM. How health conditions translate into self-ratings: a comparative study of older adults across Europe. $J$ Health Soc Behav 2014;55:320-41.

21. Guzman-Castillo M, Ahmadi-Abhari S, Bandosz P, et al. Forecasted trends in disability and life expectancy in England and Wales up to 2025: a modelling study. Lancet Public Health 2017; 2:e307-e313.

22. Jagger $\mathrm{C}$, Matthews FE, Wohland $\mathrm{P}$, et al. A comparison of health expectancies over two decades in England: results of the Cognitive Function and Ageing Study I and II. Lancet 2016; 387:779-86.

23. Rockwood K. What can we expect of health in old age? Lancet 2016;387:730-1. 